\title{
Aluminium induced texturing of glass substrates with improved light management for thin film solar cells
}

\author{
Marta Lluscà ${ }^{a}$, , Félix Urbain ${ }^{b}$, Vladimir Smirnov ${ }^{b}$, Aldrin Antony ${ }^{\text {a,c }}$, Jordi \\ Andreu $^{\mathrm{a}}$ and Joan Bertomeu ${ }^{\mathrm{a}}$
}

${ }^{a}$ Department of Applied Physics and Optics, Universitat de Barcelona, 08028 Barcelona, Spain

${ }^{b}$ IEK-5 Photovoltaik, Forschungszentrum Jülich GmbH, D-52425 Jülich, Germany

${ }^{c}$ Department of Energy Science and Engineering, Indian Institute of Technology Bombay, 400076

Mumbai, India

*E-mail: marta.llusca@ub.edu; Tel: +349340 39223

\begin{abstract}
Aluminium induced texturing (AIT) method has been used to texture glass substrates to enhance photon absorption in microcrystalline thin film Si solar cells. In this process, a thin $\mathrm{Al}$ film is deposited on a glass substrate and a non-uniform redox reaction between the glass and the Al film occurs when they are annealed at high temperature. After etching the reaction products, the resultant glass surface presents a uniform and rough morphology. In this work, three different textures $\left(\sigma_{\mathrm{rms}} \sim 85, \sim 95, \sim 125 \mathrm{~nm}\right)$ have been achieved by tuning the dc sputtering power and over them and over smooth glass, pin microcrystalline silicon solar cells have been fabricated. The cells deposited over the textured substrates showed an efficiency improvement in comparison to the cells deposited over the smooth glass. The best result was given for the glass texture $\sigma_{\mathrm{rms}} \sim 125 \mathrm{~nm}$ that led to an average efficiency $2.1 \%$ higher than that given by the cell deposited on smooth glass.
\end{abstract}

\section{Introduction}

For thin film silicon solar cells efficient light management plays a crucial role to improve device performance [1]. A common approach to improve light management involves introduction of textured interfaces in the solar cell. Scattering at the interfaces increases the path length of incident light aiming in higher absorption in the active layer and hence, higher conversion efficiency. 
In thin film silicon solar cells, light scattering is usually achieved by texturing the front transparent conducting oxide (TCO) [2, 3, 4], the back reflector [5], or even the substrate with either random $[6,7]$ or periodic $[8,9]$ textures with typical roughness in

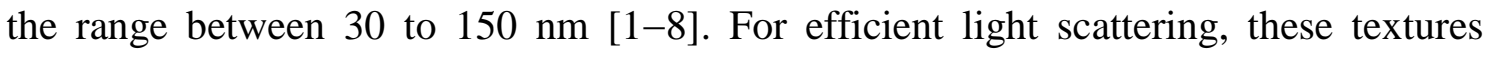
should be in the dimension range of the incoming light wavelength [10].

Typical textured TCOs are the naturally textured $\mathrm{ZnO}: \mathrm{B}$ grown by Low Pressure Chemical Vapour Deposition (LPCVD) [2], $\mathrm{SnO}_{2}: \mathrm{F}$ grown by Atmospheric Pressure Chemical Vapour Deposition (APCVD) [3], or sputtered and HCl-etched ZnO:Al (AZO) [5]. Besides these "traditional" light trapping schemes, other nanoscale approaches are currently under investigation including photonic crystals [11], nanowires [12], and periodic or periodic-disordered nanostructures [13].

Texturing the substrate is a good alternative compared to texturing the TCO or the back reflector. An optimized textured glass surface will provide a wider range of TCOs which are suitable for thin film solar cells, for example non-texturable TCOs or alternative front contacts, such as carbon nanotubes [14]. Moreover texturing the glass gives the possibility for two fold light scattering at two interfaces (glass/TCO and TCO/silicon) as exhibited in Fig. 1.

In this work the Aluminium Induced Texturing method (AIT) has been used to texture Borofloat glass substrates. In this method, a thin Al film is deposited onto a glass substrate and a redox reaction between the $\mathrm{Al}$ and the $\mathrm{SiO}_{2}$ of the glass is induced by high temperature annealing. The reaction products are wet-etched and the result is a uniform and rough glass surface [15]. The final roughness can be controlled by varying the process parameters such as the etching solution [16, 17], the etching time [18], the initial Al thickness [6], the annealing conditions [18] or the Al deposition method [6]. The AIT method can create suitable substrate textures for polysilicon solar cells [16-19] as well as for amorphous and microcrystalline thin film silicon solar cells [18].

In this study, the glass roughness has been controlled by varying the dc sputtering power to deposit the $\mathrm{Al}$, and textures with roughness values of $\sim 85 \mathrm{~nm}$ (sample T1), $\sim 95 \mathrm{~nm}$ (sample T2) and $125 \mathrm{~nm}$ (sample T3) have been obtained. Over these textures and over smooth glass, an AZO film of $800 \mathrm{~nm}$ has been deposited followed by identical $\mu \mathrm{c}-\mathrm{Si}: \mathrm{H}$ pin solar cells. $J-V$ measurements have confirmed the suitability of 
these textures for the growth of $\mu \mathrm{c}-\mathrm{Si}: \mathrm{H}$ and have shown an increase in the short circuit current that results in an overall efficiency improvement in comparison to the solar cell on flat substrate.

\section{Experimental}

Three Borofloat 33 glass substrates of $2 \mathrm{~mm}$ thick were cleaned in an ISO 7 (10000 type) clean room. Al films of $180 \mathrm{~nm}$ were deposited by means of direct current (dc) magnetron sputtering at $60 \mathrm{~W}$ (sample T1), $100 \mathrm{~W}$ (sample T2) and $150 \mathrm{~W}$ (sample T3) over the three cleaned substrates. The Al target was $99.999 \%$ pure and had a diameter of 3 inch. The samples were post-annealed at $600^{\circ} \mathrm{C}$ during $1 \mathrm{~h}$ to induce the chemical reaction between the glass surface and the Al layer and the reaction products were etched with $\mathrm{H}_{3} \mathrm{PO}_{4}$ at $185^{\circ} \mathrm{C}$.

Over the resultant textured substrates (T1, T2 and T3) and over the non-textured Borofloat glass (referred to as T0), $800 \mathrm{~nm}$ of $\mathrm{AZO}$ ( $\mathrm{ZnO}$ with $2 \mathrm{wt} \% \mathrm{Al}_{2} \mathrm{O}_{3}$ and 99.99\% pure) were deposited by dc magnetron sputtering at a substrate temperature of $300^{\circ} \mathrm{C}$, using a power density of $220 \mathrm{~W}$ and at an Ar pressure of $0.4 \mathrm{~Pa}$.

The morphological study was carried out using a Scanning Electron Microscope (SEM) and an Atomic Force Microscope (AFM). SEM micrographs were obtained through a Nova Nano SEM 230 from FEI Electron Microscope. Insulating samples had to be covered with thin Au layers to avoid the charging of the surface. AFM images were recorded using a Pacific Instruments system and the software used for the image analysis was XEI 1.7.3 of Psia Inc. and the $\sigma_{r m s}$ values were extracted from areas of $15 \times 15 \mu \mathrm{m}^{2}$.

The total transmittance $(T)$ and diffused transmittance $\left(T_{d}\right)$ measurements in the wavelength range 350-1400 nm were recorded using a PerkinElmer Lambda 950 spectrophotometer equipped with a $150 \mathrm{~mm}$ integrating sphere. The haze values were calculated from the quotient between the $T_{d}$ and $T$ according to:

$$
\text { Haze }=T_{\mathrm{d}} / T
$$

The sheet resistance $\left(R_{\mathrm{S}}\right)$ of glass/AZO samples was measured by using a four point probe system (Jandel RM3).

Thin film silicon solar cells were deposited on the AZO coated textured glasses and

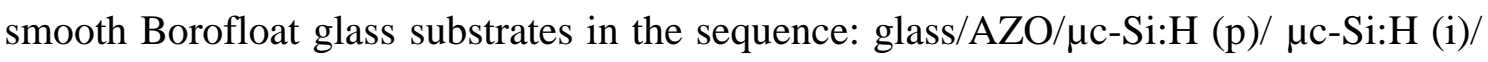


$\mu \mathrm{c}-\mathrm{SiOx}: \mathrm{H}(\mathrm{n})$. The cells were covered with radio frequency magnetron sputtered $\mathrm{ZnO}$ :Al layer and Ag contact deposited with $1 \mathrm{~cm}^{2}$ mask to define the cell area. Twelve such identical solar cells were fabricated on each of the substrates tested. The schematic cross section of a solar cell is shown in Fig. 1. The thicknesses of the intrinsic and the doped silicon layers are $1100 \pm 25$ and $20 \pm 5 \mathrm{~nm}$, respectively. Additional details on the deposition process can be found elsewhere [20].

Solar cells were characterised by current-voltage $(J-V)$ measurements under AM1.5 illumination using a double source (class A) sun simulator, and by external quantum efficiency (EQE) measurements. The total optical reflection of the cells was measured using a PerkinElmer Lambda 950 spectrophotometer within a spectral range from 300 to $1300 \mathrm{~nm}$. Although various cells were fabricated on every substrate, the total reflectance, the EQE, and the $J$ - $V$ curves shown in this work belong to the best solar cell (highest efficiency) in each one. The average values of the solar cell parameters shown in Table II were calculated from all the cells except for those presenting short circuit problems which were 1 or 2 per substrate).

\section{Results and discussion}

The morphology of T1, T2, T3 and AZO coated samples, T1/AZO, T2/AZO and T3/AZO is studied using SEM and the images recorded at a tilt angle of $60^{\circ}$ is presented in Fig. 2.

By increasing the dc sputtering power, the Al particles reach the glass with higher energy and the Al film grows more compact and with greater adhesion to the glass substrate. As a result, the glass surface gets more textured. At dc sputtering powers $<100 \mathrm{~W}$, the glass surface presents a U-shape crater morphology (see Fig. 2 a) and c)) with lateral feature sizes of $500-900 \mathrm{~nm}$. When the sputtering is performed at $150 \mathrm{~W}$ (see Fig. 2 e)) the glass surface becomes highly rough with deeper valleys and smaller lateral sizes. Probably at such high power, the Al atoms have diffused deeper into the glass surface and after completing the AIT process, the result is this highly porous-like structure. 
After depositing $800 \mathrm{~nm}$ of AZO, the three surfaces present a double texture morphology based on a superposition of a micro- and nano-metric roughness similar to a "cauliflower" surface.

The roughness values can be found in Table $I$ and the haze curves in the range 350-1400 nm are presented in Fig. 3. In accordance with the SEM images, both roughness values and haze factor of the textured glasses are found to increase with the sputtering power. When the textured glasses are coated with the AZO, the roughness and haze values are almost unchanged. Only the highest texture, T3, seems to be slightly smoothened which is beneficial to avoid the formation of cracks during the $\mu \mathrm{c}-$ $\mathrm{Si}: \mathrm{H}$ growth.

A summary with the roughness, sheet resistance, haze value at $600 \mathrm{~nm}$ and integrated transmittance in the range $400-1100 \mathrm{~nm}$ of all the samples is shown in Table I. The sheet resistance of the AZO on smooth glass is $9 \Omega /$ sq and increases up to $\sim 10 \Omega / \mathrm{sq}$ over T1 and up to $\sim 12 \Omega /$ sq over T2 and T3.

Identical pin $\mu \mathrm{c}-\mathrm{Si}: \mathrm{H}$ solar cells have been fabricated over AZO coated T0, T1, T2 and $\mathrm{T} 3$ substrates followed by the back reflector $(\mathrm{TCO}+\mathrm{Ag})$ and the total reflectance of the devices in the range 300-1100 $\mathrm{nm}$ is exhibited in Fig. 4.

As can be seen from Fig. 4, the solar cells deposited on the textured substrates show a total reflectance significantly lower than that obtained in the case of smooth glass, whose average value is $R_{400-1100}=45.4 \%$. The roughness increase at the interface $\mathrm{AZO} / \mu \mathrm{c}-\mathrm{Si}: \mathrm{H}$ leads to an improved optical coupling because the refractive index varies progressively from the glass to the silicon layer, and then, the reflected light component is decreased. As higher is the surface roughness, better is the optical coupling and lower are the optical reflection losses, which suggests that texture T3/AZO in this study is the most appropriate for the fabrication of the cells, presenting an integrated reflectance of $R_{400-1100}=19.1 \%$ and showing the lowest reflection in the short wavelength range.

The fact that the glass surface of sample T3 has smaller lateral sizes than T1 and T2 could be the reason of the lower reflection at short wavelengths as it is know that smaller feature sizes are more appropriate in scattering shorter wavelengths [1]. 
The surface reflectance of the solar cell has a direct influence on the EQE of the devices. As observed in Fig. 5, the EQE curve of the device on the smooth substrate presents the typical maximum and minimum fringes produced by the optical interferences between the incoming and reflected light at the interfaces glass/AZO and $\mathrm{AZO} / \mathrm{Si}$ [21]. Thanks to the textured interfaces, the curve becomes smoother throughout the whole spectral range as already seen in related studies $[1,8,22]$. It is observed that substrate texturing significantly improves the long wavelength response $(500-1100 \mathrm{~nm})$ for all textures. In contrast, for shorter wavelengths $(\lambda<600 \mathrm{~nm})$, only the EQE of the cell on T3/AZO shows slightly greater values than that over T0/AZO, in agreement with reduced cell reflectance in the given spectral range (see Fig. 4).

Comparing the total reflection and the EQE curves, it is observed that the light trapping at long wavelengths does not depend on the degree of glass roughness. On the other hand, in the short wavelength region, small variations in the glass texture are directly affecting the EQE as well as the total reflectance of the devices. As mentioned above, the sample with the smallest lateral features is scattering more efficiently the light at short wavelengths, as a result the light trapping effect is increased.

Additionally, slight variations in the p-type layer thickness could contribute to the differences in short wavelength EQE observed in Fig. 4.

The overall $J-V$ characteristics of the best solar cells (those showing the highest efficiency values) are shown in Fig. 6, and Table II presents the best cell parameters as well as the average parameters of the solar cells on the four different substrates. The photovoltaic performance of the fabricated solar cells suggests that, the three different textures applied here have no deteriorating influence on the growth of silicon layers. The main parameter that is influenced by the substrate morphology is the short circuit current density. Considering the best cells, it is observed that the solar cells deposited over T1/AZO show an increase of $\Delta J_{\mathrm{SC}}=4.9 \mathrm{~mA} / \mathrm{cm}^{2}$ compared to the ones deposited over T0/AZO. In the case of T2/AZO, this increase is found to be much higher, with $\Delta J_{\mathrm{SC}}=5.5 \mathrm{~mA} / \mathrm{cm}^{2}$ and for the highest texture $\mathrm{T} 3$, the short circuit current density increase is $\Delta J_{\mathrm{SC}}=6.7 \mathrm{~mA} / \mathrm{cm}^{2}$. The increase in $J_{\mathrm{SC}}$ goes along with an increased efficiency of the devices, as fill factor $(F F)$ and open-circuit voltage $\left(V_{\mathrm{OC}}\right)$ are only slightly affected. The average efficiency improved from $5 \%$ to $6.5 \%$ in the case of texture $\mathrm{T} 1$ and to $6.8 \%$ and $7.1 \%$ for textures $\mathrm{T} 2$ and $\mathrm{T} 3$, respectively. As a general 
tendency, as higher is the substrate roughness, higher is the current and greater is the solar cell performance. However, it can be observed that the best cell on texture T3 possess a higher $J$ sc but the efficiency is slightly lower than for texture T2, because of the lower $V_{\mathrm{OC}}$ and $F F$. This decrease in $V$ oc and $F F$ values can be attributed to a lower carrier lifetime due to recombination at the $\mathrm{p} / \mathrm{i}$ and $\mathrm{i} / \mathrm{n}$ interfaces, as a consequence of the higher roughness. The $V_{\mathrm{OC}}$ and $F F$ of the samples with lower roughness (T0-T2) are very similar pointing to similar carrier recombination lifetimes. Probably the recombination lifetime for these samples is dominated by the bulk recombination.

AZO grown on AIT glasses is a good alternative to the commonly used $\mathrm{HCl}$ etched AZO or LPCVD ZnO:B. Microcrystalline silicon thin film solar cells grown on AZOcovered AIT substrates have shown similar enhancement in the current density values than that given by $\mu \mathrm{c}-\mathrm{Si}: \mathrm{H}$ grown on sputtered and etched AZO [20]. In the case of cells grown on pyramidal LPCVD $\mathrm{ZnO}: \mathrm{B}$, the improvement of the solar cell parameters has been reported to be higher [23]. However, to achieve a uniform and soft pyramid morphology adequate for the growth of microcrystalline silicon, needs a complex optimization and often, post-deposition treatments such as Ar plasma etching are also required $[2,23]$.

\section{Conclusions}

The AIT method has been used to create different types of textures on Borofloat glass substrates. The textures were achieved by sputtering the $\mathrm{Al}$ at 60, 100 and $150 \mathrm{~W}$, followed by the AIT process, which yielded roughness of $\sim 85 \mathrm{~nm}$ (texture T1), $\sim 95 \mathrm{~nm}$ (texture T2) and $\sim 125 \mathrm{~nm}$ (texture T3), respectively. Over these textures and over smooth Borofloat glass, $800 \mathrm{~nm}$ of AZO was deposited by means of dc magnetron sputtering and for the three textures, the resultant surfaces exhibit a double texture morphology (the superposition of a micro and a nanotexture) without deep valleys or sharp edges that may negatively influence the performance of the cells. The haze values at $600 \mathrm{~nm}$ were $15 \%$ for T1/AZO, $23.7 \%$ for T2/AZO and $29.5 \%$ for T3/AZO and the sheet resistances were lower than $12 \Omega /$ sq.

Subsequently $\mu \mathrm{c}-\mathrm{Si}: \mathrm{H}$ solar cells of $1 \mathrm{~cm}^{2}$ were deposited over T1/AZO, T2/AZO, T3/AZO and over AZO coated smooth glass. The electrical characterization of the cells 
demonstrate that the AIT method is able to perform suitable textures for $\mu \mathrm{c}-\mathrm{Si}: \mathrm{H}$ solar cells, the cells grew without shunting and in every case gave increased short circuit current values compared to the cells grown on smooth substrates. The integrated reflectance in the range $400-1100 \mathrm{~nm}$ of the whole devices had lower values in comparison to the smooth glass and the EQE was smoothened and highly improved at longer wavelengths $(500-1100 \mathrm{~nm})$. Considering the average solar cell parameters, when higher was the substrate roughness, higher was the current and greater was the efficiency, in the case of texture T3 $(\sim 125 \mathrm{~nm})$, the average cell efficiency was improved by $2.1 \%$ relative to the solar cells on smooth substrate.

\section{Acknowledgements}

This work has been supported by the Ministerio de Economía y Competitividad and the European Regional Development Fund through the projects INNDISOL (IPT-4200002010-6) and HELLO (ENE2013-48629-C4-2-R).

\section{References}

[1] J. Müller, B. Rech, J. Springer, M. Vanecek, TCO and light trapping in silicon thin film solar cells, Sol. Energy, 77 (2004) 917-930.

[2] S. Faÿ, J. Steinhauser, S. Nicolay, C. Ballif, Polycrystalline ZnO: B grown by LPCVD as TCO for thin film silicon solar cells, Thin Solid Films, 518 (2010) 29612966.

[3] Z. Remes, M. Vanecek, H.M. Yates, P. Evans, D.W. Sheel, Optical properties of $\mathrm{SnO}_{2}: \mathrm{F}$ films deposited by atmospheric pressure CVD, Thin Solid Films, 517 (2009) 6287-6289.

[4] C. Beneking, H. Wagner, A. Lo, Texture etched $\mathrm{ZnO}$ :Al coated glass substrates for silicon based thin film solar cells, Thin Solid Films, 351 (1999) 247-253.

[5] W. Böttler, V. Smirnov, J. Hüpkes, F. Finger, Texture-etched $\mathrm{ZnO}$ as a versatile base for optical back reflectors with well-designed surface morphologies for application in thin film solar cells, Phys. Status Solidi A, 209 (2012) 1144-1149.

[6] M. Lluscà, A. Antony, J. Bertomeu, Growth and properties of $\mathrm{ZnO}: \mathrm{Al}$ on textured glass for thin film silicon solar cells, Int. J. Photoenergy, 2014 (2014). 
[7] W. Zhang, E. Bunte, J. Worbs, H. Siekmann, J. Kirchhoff, A. Gordijn, J. Hüpkes, Rough glass by $3 \mathrm{~d}$ texture transfer for silicon thin film solar cells, Phys. Status Solidi C, 74 (2010) 1120-1123.

[8] V. Terrazzoni-Daudrix, J. Guillet, X. Niquille, L. Feitknecht, F. Freitas, P. Winkler, A. Shah, R. Mor, D. Fischer, Enhanced light trapping in thin film silicon solar cells deposited on PET and glass Fabrication methods, in 3rd World Conference on Photovoltaic Energy Conversion, pp. 1596-1600, 2003.

[9] H. Stiebig, C. Haase, C. Zahren, B. Rech, N. Senoussaoui, Thin film silicon solar cells with grating couplers. An experimental and numerical study, J. Non-Cryst. Solids, 352 (2006) 1949-1952.

[10] T. Soderstrom, F. J. Haug, X. Niquille, C. Ballif, TCOs for Nip Thin Film Silicon Solar Cells, Prog. Photovoltaics: Res. Appl. 17 (2008) 165-176.

[11] P. Bermel, C. Luo, L. Zeng, L. C. Kimerling, J. D. Joannopoulos, Improving thin film crystalline silicon solar cell efficiencies with photonic crystals, Opt. Express, 15 (2007) 16986-17000.

[12] B. Liu, E. S. Aydil, Growth of Oriented Single-Crystalline Rutile $\mathrm{TiO}_{2}$ Nanorods on Transparent Conducting Substrates for Dye-Sensitized Solar Cells, J. Am. Chem. Soc. 131 (2009) 3985-3990.

[13] U. W. Paetzold. M. Smeets, M. Meier, K. Bittkau, T. Merdzhanova, V. Smirnov, D. Michaelis, C. Waechter, R. Carius, U. Rau, Disorder improves nanophotonic light trapping in thin-film solar cells, Appl. Phys. Lett. 104, 131102 (2014).

[14] M. A. Contreras, T. Barnes, J. V. D. Lagemaat, G. Rumbles, T. J. Coutts, C. Weeks, P. Glatkowski, I. Levitsky, J. Peltola, D. A. Britz, Replacement of Transparent Conductive Oxides by Single-Wall Carbon Nanotubes in $\mathrm{Cu}$ (In, Ga) Se2 -Based Solar Cells, J. Phys. Chem. Lett. C, 111 (2007) 14045-14048.

[15] P. I. Widenborg, A. G. Aberle, Polycrystalline Silicon Thin-Film Solar Cells on AIT-Textured Glass Superstrates, Adv. Optoelectron. 2007 (2007) 1-7.

[16] N. Chuangsuwanich, P. Campbell, P.I. Widenborg, A. Straub, A. G. Aberle, Light trapping properties of evaporated poly-silicon films on AIT-textured glass substrates, Conference Record of the 31st IEEE Photovoltaic Specialists Conference, pp. 11611164, 2005.

[17] G. Jin, P. I. Widenborg, P. Campbell, S. Varlamov, "Lambertian matched absorption enhancement in PECVD poly-Si thin film on aluminum induced textured 
glass superstrates for solar cell applications, Prog. Photovoltaics: Res. Appl. 18 (2010) $582-589$.

[18] J. Wang, S. Venkataraj, C. Battaglia, P. Vayalakkaraa, A.G. Aberle, Analysis of optical and morphological properties of aluminium Induced Texture Glass Superstrates, Jpn. J. of Appl. Phys, 51 (2012).

[19] H. Cui, M. A. Green, P.R. Campbell, M. J. Wolff, G. Jin, Enhanced Absorption of SPC Poly-Si Thin Films on Aluminium Induced Textured (AIT) Glass with Submicron Texture Feature Size in proceedings at 25th EU PVSEC/5th World Conference on Photovoltaic Energy Conversion (WCPEC-5), Valencia, Spain, 6-10 September 2010, pp. 3691-3694.

[20] V. Smirnov, A. Lambertz, F. Finger, Bifacial microcrystalline silicon solar cells with improved performance due to $\mu \mathrm{c}-\mathrm{SiO}_{x}: \mathrm{H}$ doped layers, Can. J. Phys. 92 (2014) 913-916.

[21] N. Senoussaoui, T. Repmann, T. Brammer, H. Stiebig, H. Wagner, Optical Properties of Microcrystalline Thin Film Solar Cells, Rev. Energ. Ren. 3 (2000) 49-56.

[22] P.I. Widenborg, A.G. Aberle, Polycrystalline Silicon thin film solar cells on AITTextured Glass Superstrates, Adv. Optoelectron. 2007 (2007) 1-7.

[23] C. Ballif, J. Bailat, D. Dominé, J. Steinhauser, S. Fäy, M. Phyton, L. Feitknecht, Fabrication of high efficiency microcrystalline and micromorph thin film solar cells on LPCVD $\mathrm{ZnO}$ coated glass substrates, in $21^{\text {st }}$ European Photovoltaic Solar Energy Conference (2006) 1552-1555. 


\section{List of Tables}

Table I. Roughness $\left(\sigma_{r m s}\right)$, sheet resistance $(R s)$, haze at $600 \mathrm{~nm}$ and integrated transmittance $(T)$ in the range 400-1100 nm of T0/AZO, T1, T2, T3, T1/AZO, T2/AZO and T3/AZO.

\begin{tabular}{|c|c|c|c|c|}
\hline Sample & $\sigma_{r m s}(\mathrm{~nm})$ & $\begin{array}{c}\text { Haze }(\%) \\
(600 \mathrm{~nm})\end{array}$ & $\begin{array}{c}\text { Integrated } T(\%) \\
(400-1100 \mathrm{~nm})\end{array}$ & $\begin{array}{c}R s \\
(\Omega / \mathrm{sq})\end{array}$ \\
\hline T0/AZO & --- & --- & 79.2 & 9 \\
T1 & $80-90$ & 15.0 & 92.6 & --- \\
T1/AZO & $80-90$ & 15.0 & 80.8 & 10 \\
T2 & $90-100$ & 21.2 & 93.7 & --- \\
T2/AZO & $90-100$ & 23.7 & 77.6 & $10-12$ \\
T3 & $120-130$ & 31.0 & 89.9 & --- \\
T3/AZO & $90-100$ & 29.5 & 74.5 & $10-12$ \\
\hline
\end{tabular}

Table II: Average and best values (highest efficiency) of solar cell parameters under AM1.5G illumination for the cells $\left(1 \mathrm{~cm}^{2}\right)$ on different substrates.

\begin{tabular}{|c|c|c|c|c|c|c|c|c|c|c|c|c|}
\hline \multirow{2}{*}{ Sample } & \multicolumn{2}{|c|}{ Eff (\%) } & \multicolumn{2}{|c|}{$F F(\%)$} & \multicolumn{2}{c|}{$V_{\mathrm{OC}}(\mathrm{mV})$} & \multicolumn{2}{c|}{$\begin{array}{c}J \mathrm{sc} \\
\left(\mathrm{mA} / \mathrm{cm}^{2}\right)\end{array}$} & \multicolumn{2}{c|}{$R \mathrm{~s}\left(\Omega \cdot \mathrm{cm}^{2}\right)$} & \multicolumn{2}{|c|}{$R \mathrm{sh}\left(\Omega \cdot \mathrm{cm}^{2}\right)$} \\
\cline { 2 - 13 } & Best & Av. & Best & Av. & Best & Av. & Best & Av. & Best & Av. & Best & Av. \\
\hline T0 & 5.2 & 5.0 & 69.6 & 69.8 & 521 & 522 & 14.3 & 13.6 & 4.08 & 4.67 & 992 & 1076 \\
T1 & 6.8 & 6.5 & 68.8 & 68.9 & 522 & 519 & 18.9 & 18.3 & 3.41 & 4.27 & 696 & 1505 \\
T2 & 7.4 & 6.8 & 71.2 & 69.5 & 525 & 523 & 19.8 & 18.7 & 5.11 & 372 & 1655 & 960 \\
T3 & 7.2 & 7.1 & 66.5 & 67.2 & 519 & 520 & 21.0 & 20.4 & 3.67 & 3.99 & 727 & 845 \\
\hline
\end{tabular}




\section{Figure captions}

Figure 1. Schematic light path of a pin thin film silicon solar cell deposited on a textured glass surface.

Figure 2. SEM images recorded at a tilt angle of $60^{\circ}$ of the textured glass substrates achieved by sputtering the $\mathrm{Al}$ at different powers and the resultant surface morphology after depositing $800 \mathrm{~nm}$ of AZO. a) Texture T1, $60 \mathrm{~W}, \mathrm{~b}$ ) Texture T1/AZO, c) Texture T2, $100 \mathrm{~W}, \mathrm{~d}$ ) Texture T2/AZO, e) Texture T3, $150 \mathrm{~W}$, and f) Texture T3/AZO.

Figure 3. Haze for samples T1, T2 and T3, T1/AZO, T2/AZO and T3/AZO in the range $350-1400 \mathrm{~nm}$.

Figure 4. Reflectance curves of the best solar cells deposited on T0, T1, T2 and T3 and integrated reflectance values in the range $400-1100 \mathrm{~nm}$.

Figure 5. Comparison between the quantum efficiency curves obtained for the best solar cells on each of the substrates tested.

Figure 6: $J-V$ curves under AM1.5G illumination for the best solar cells deposited on the different substrates. 
Figure 1

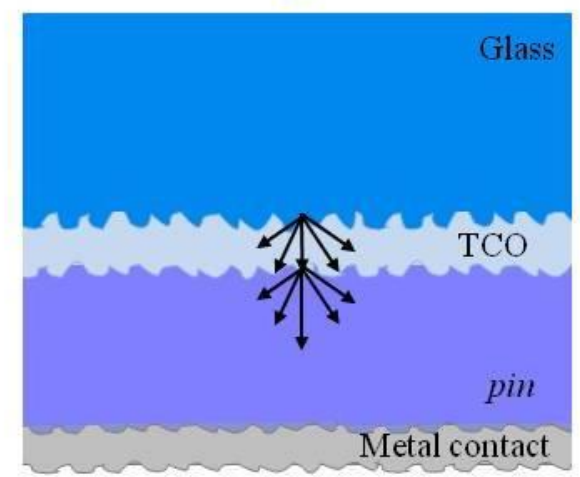


Figure 2

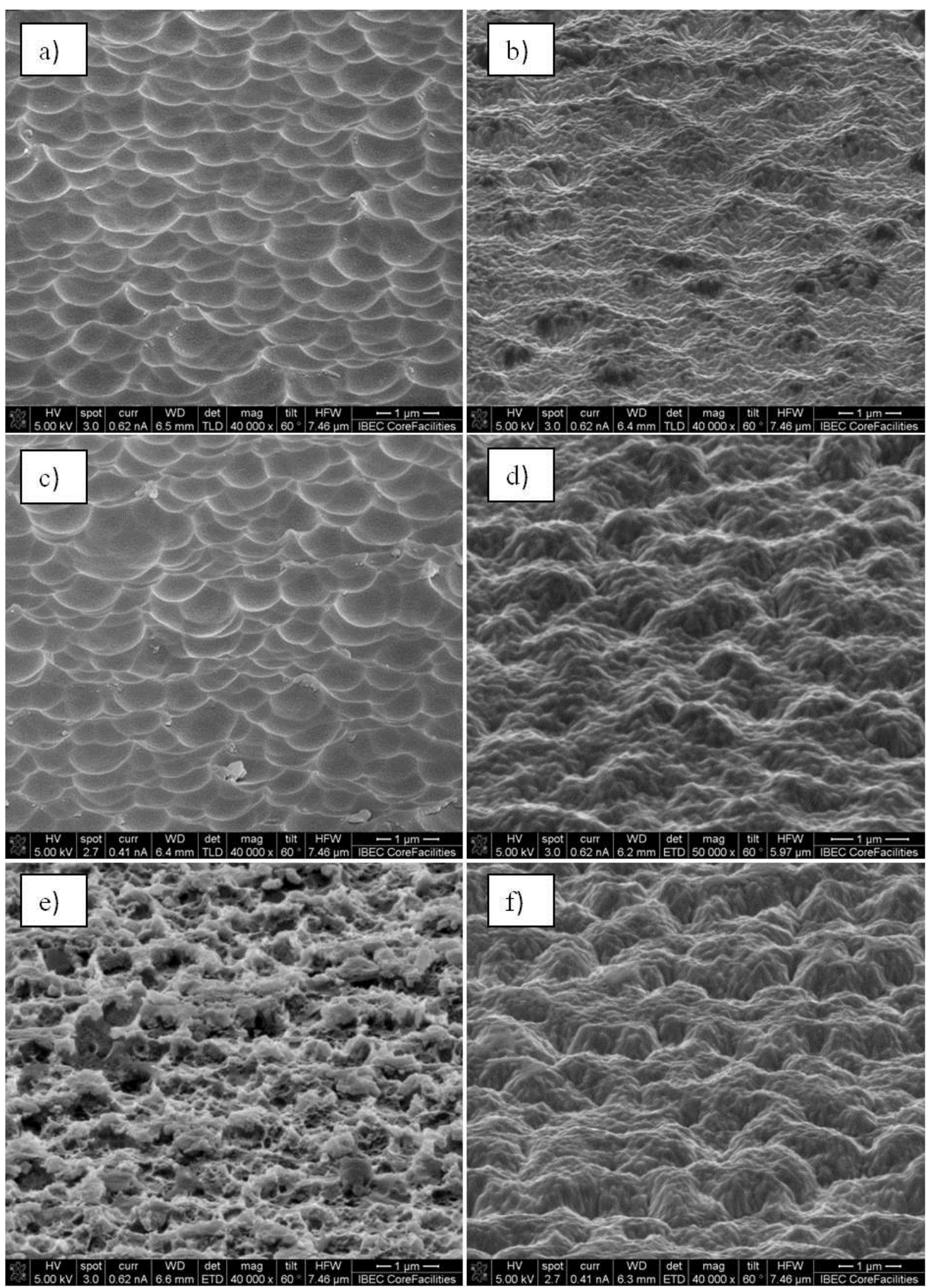


Figure 3

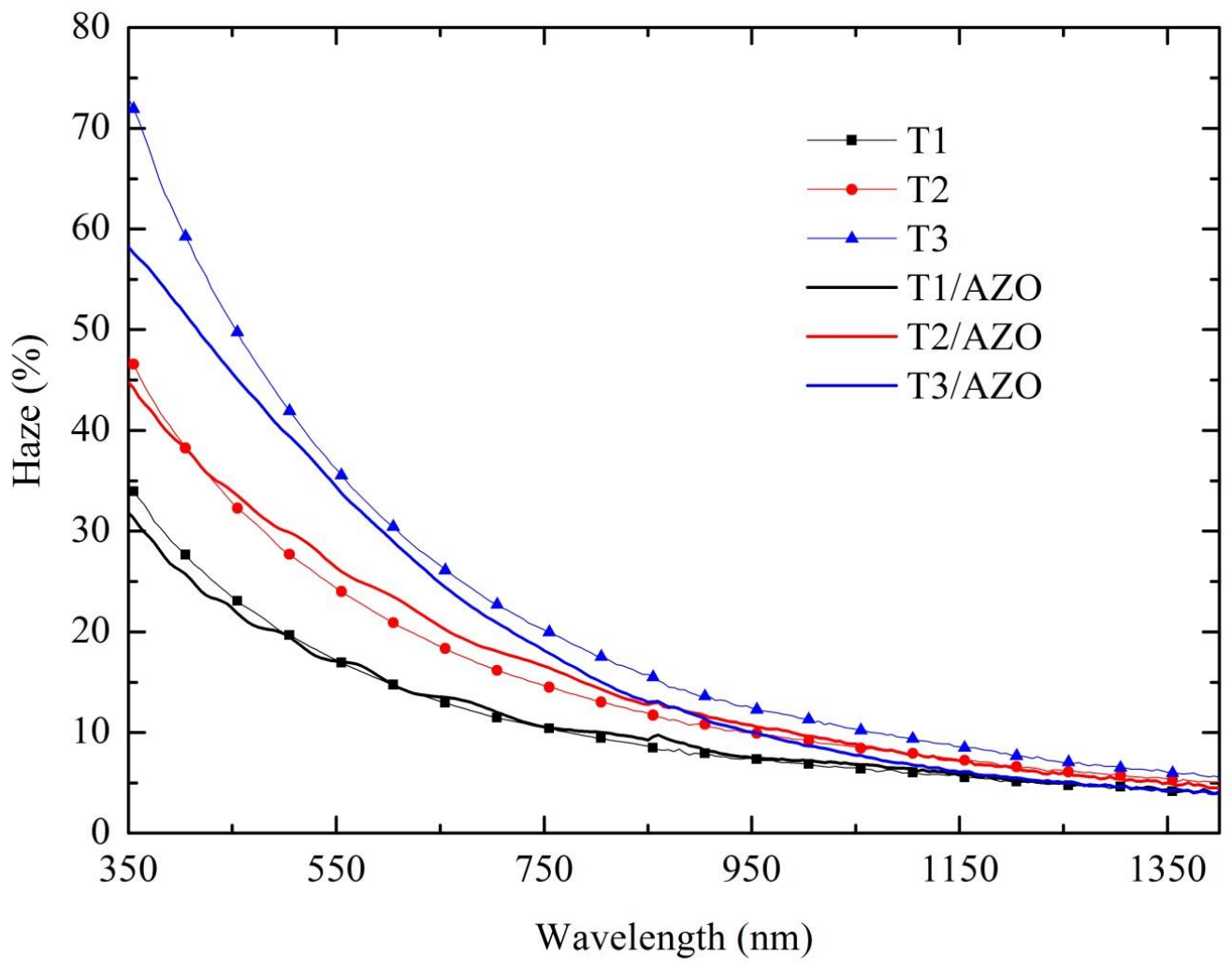


Figure 4

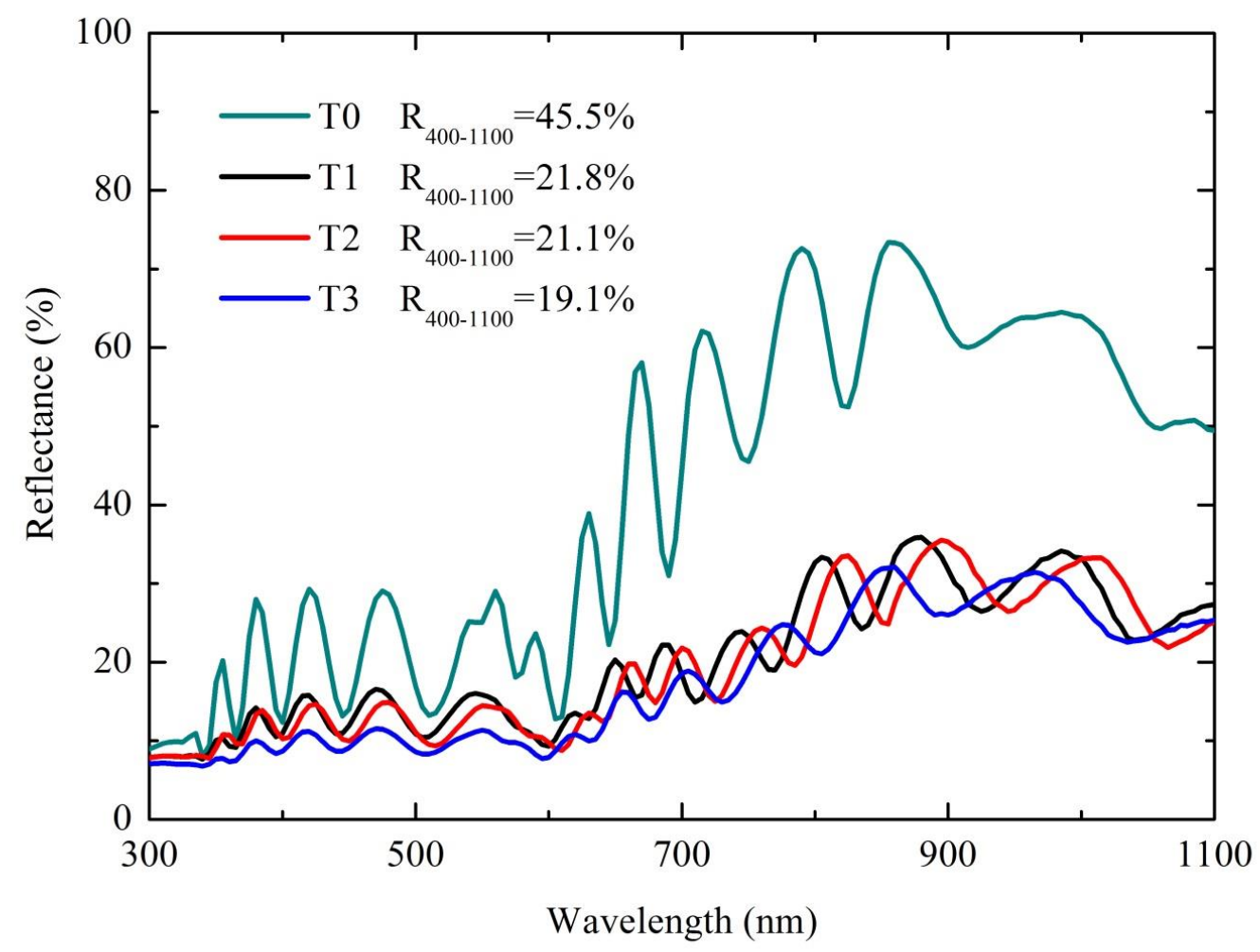


Figure 5

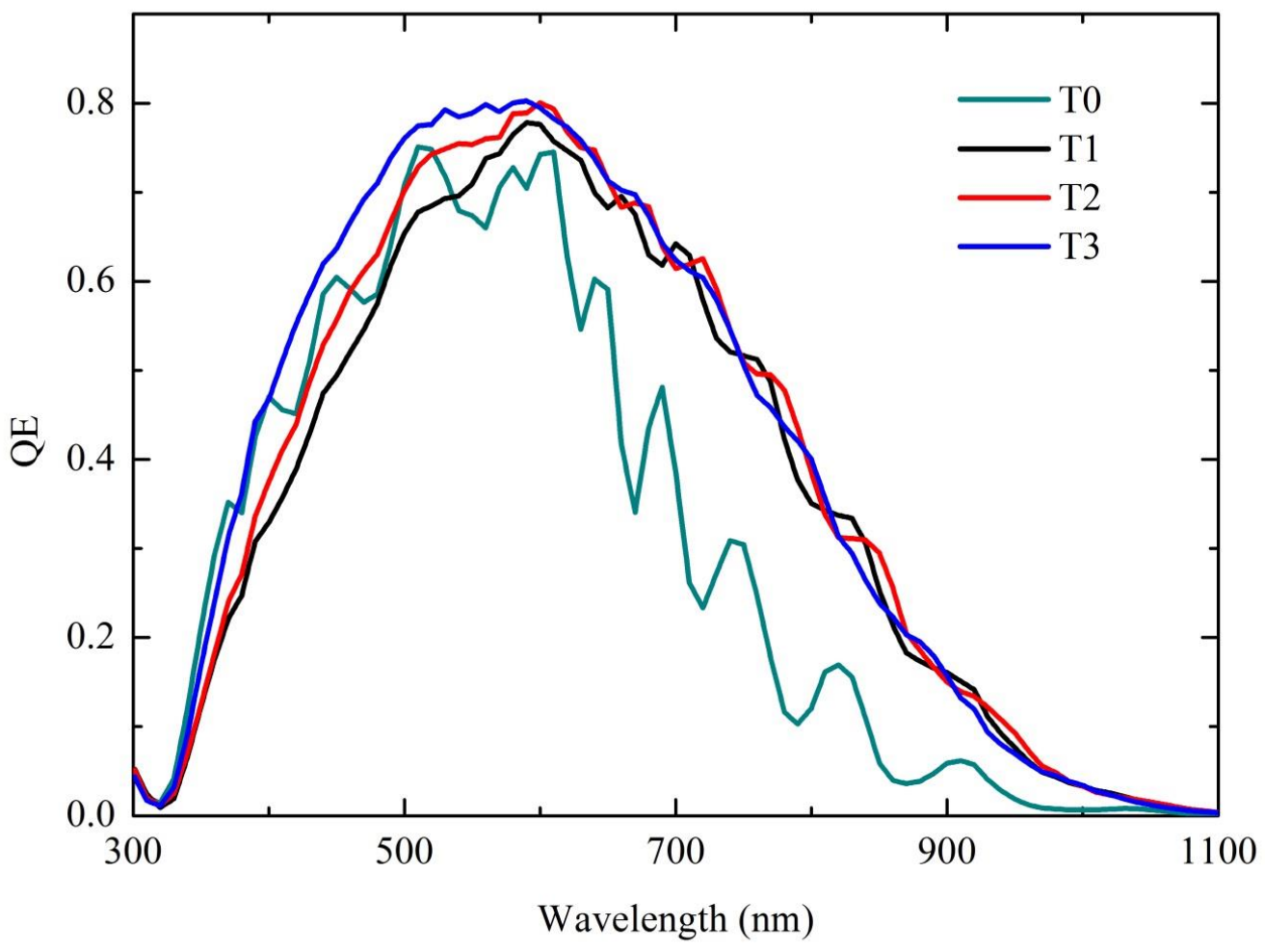


Figure 6

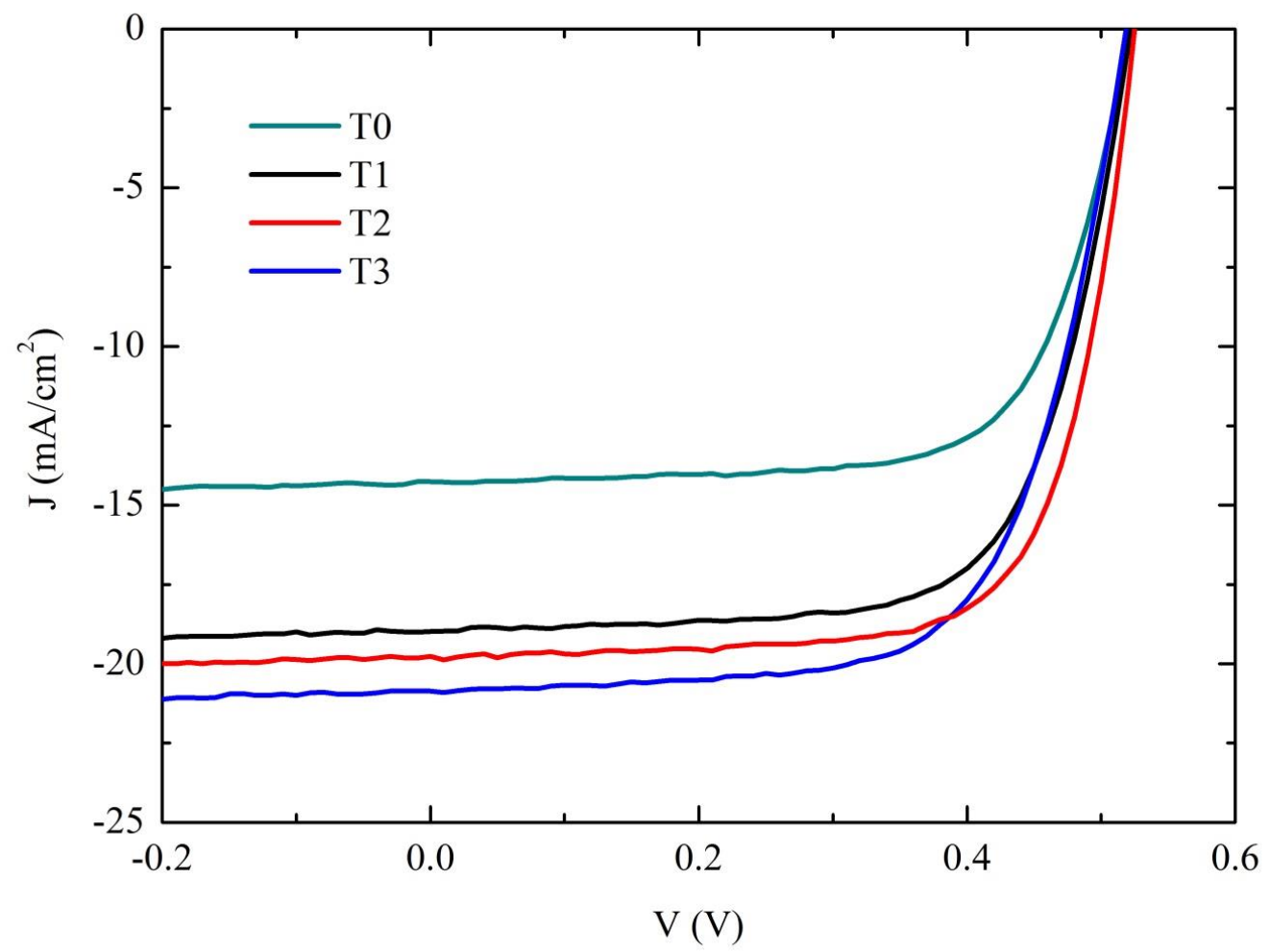

